\title{
THE BIG PICTURE
}

\section{Where there's life ...}

\section{Rebecca Coombes head of news and views}

The BMJ

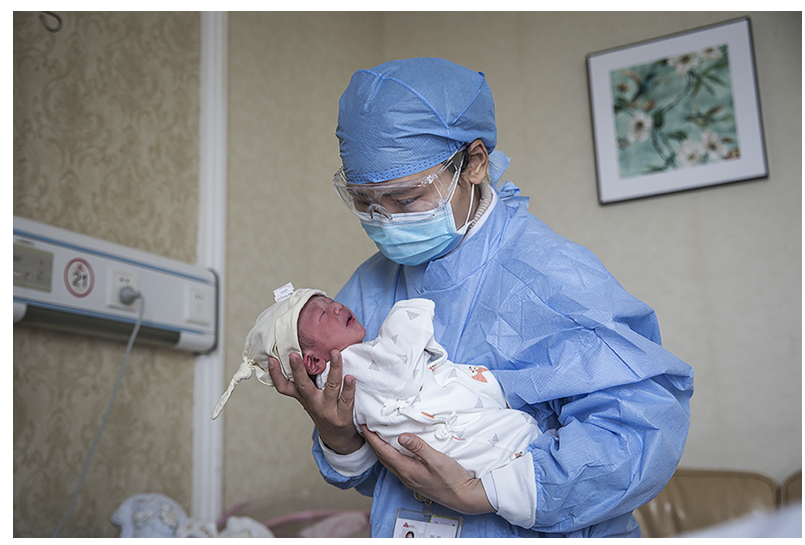

China has announced that it will lift the lockdown on Wuhan, the city at the centre of the covid-19 pandemic, on 8 April, nearly 11 weeks since it was imposed. Similar lockdown measures are being lifted across Hubei province, which has seen the majority of the country's infections and deaths.

As at Tuesday 24 March, Hubei has seen 67801 cases and 3160 deaths. Doctors and nurses in Hubei province are now beginning to scale back efforts and returning to their homes.

[Image: Getty Images]

A nurse in a protective suit attends to a baby in an isolation ward at Wuhan Children's Hospital. 